\title{
Carbon Source Regulation of Nicotinamide Adenine Dinucleotide (Phosphate) Glycohydrolase in Neurospora crassa: Induction and Repression of Enzyme Synthesis
}

\author{
By JOÃO A. JORGE ${ }^{*}$ AND HÉCTOR F. TERENZI ${ }^{2}$ \\ Departamento de Biologia, Faculdade de Filosofia, Ciências e Letras de Ribeirão Preto ${ }^{1}$ and \\ Departamentos de Fisiologia e Bioquímica, Faculdade de Medicina de Ribeirão Preto ${ }^{2}$, \\ Universidade de São Paulo, 14100 - Ribeirão Preto, Estado de São Paulo, Brasil
}

(Received 17 January 1984; revised 21 February 1984)

Synthesis and release of NAD(P)ase by Neurospora crassa wild type was studied in experiments in which mycelia grown in Vogel minimal medium were transferred to media containing protein as the only carbon source. Several results are presented suggesting that the NAD(P)ase may be induced by the presence of protein in the culture medium. Low concentrations of sucrose or glucose $(0.1 \%)$, Casamino acids or some amino acids such as methionine, cysteine, phenylalanine and tryptophan strongly repressed the enzyme synthesis. Under induction conditions NAD(P)ase and alkaline protease appeared together in the culture medium. It would appear that $\mathrm{NAD}(\mathrm{P})$ ase and alkaline protease are coordinately regulated by a common control mechanism related to carbon catabolism.

\section{INTRODUCTION}

Nicotinamide adenine dinucleotide (phosphate) glycohydrolase (NAD(P)ase; EC 3.2.2.6) was first described, in Neurospora crassa, as an enzyme that has its level increased in mycelia grown in a zinc-deficient medium (Nason et al., 1951). Following this discovery Zalokar \& Cochrane (1956) found that NAD(P)ase activity increased sharply during conidiation. Stine (1968) showed that NAD(P)ase activity appeared together with the formation of aerial hyphae, accumulating in conidia and decreasing very fast as the mature conidia germinated. Combépine \& Turian (1970) concluded that NAD(P)ase was important to conidiogenesis. A mutant that was temperature sensitive for conidiation was also temperature sensitive for NAD(P)ase formation (Hochberg \& Sargent, 1974). Urey (1971) was also able to separate the conidiophores from the mycelial pad and to demonstrate that newly formed NAD(P)ase activity was confined to developing aerial tissue. We showed (Jorge \& Terenzi, 1980) that the cyclic AMP-deficient, hyperconidiating mutant, strain $c r-1$ (crisp-1) continuously produces and secretes NAD(P)ase, and that the enzyme level decreases when the mutant is cultivated in the presence of cyclic AMP, which also corrects the morphology defect. However, conidiation does not seem to be a prerequisite for the production of NAD(P)ase, since the aconidial strain fluffy makes large amounts of the enzyme (Stine, 1968). On the other hand, the absence of NAD(P)ase did not affect the growth of aerial hyphae, conidiation or conidial germination in five defective mutant strains (nada) studied (Nelson et al., 1975).

Nelson et al. (1976) concluded that NAD(P)ase is developmentally regulated, but is not required for cell differentiation. Thus, NAD(P)ase is in some way correlated with aerial hyphae formation and conidiogenesis, but its physiological role is still obscure.

The objective of this study was to investigate the nutritional conditions which influence NAD(P)ase level. We found that NAD(P)ase production was increased when the mycelium was

Abbreviation: PMSF, phenylmethylsulphonyl fluoride. 
incubated in liquid minimal medium with protein as the sole carbon source. Under these conditions, NAD(P)ase production occurred even in agitated cultures. We also provide evidence suggesting that NAD(P)ase and protease may be co-regulated.

\section{METHODS}

Culture conditions. A wild type strain of Neurospora crassa (FGSC 424) was grown on slants of solid minimal medium (Vogel, 1956). Conidia were collected from 7-10-d-old cultures and inoculated at a concentration of $10^{7}$ cells $\mathrm{ml}^{-1}$ into Vogel minimal medium containing $2 \%(\mathrm{w} / \mathrm{v})$ sucrose. The culturing was performed as indicated in the legends to the figure and tables. Incubations were carried out at $30^{\circ} \mathrm{C}$ in a rotatory shaker at 120 r.p.m. After a period of incubation to allow mycelial development, the mycelia were collected, washed and resuspended in Vogel salts supplemented with different carbon sources as indicated for each experiment, and incubated as before. For experiments on enzyme induction we used $15-20 \mathrm{mg}$ (dry wt) mycelia per $25 \mathrm{ml}$ medium.

Measurements of enzyme activities. NAD(P)ase activity was determined by the method of Kaplan et al. (1951).

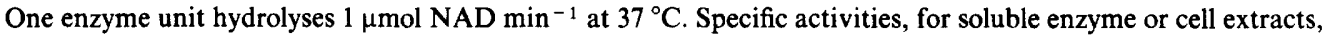
are expressed as units per mg dry wt of cells.

Alkaline protease was assayed by spectrophotometric measurement of released tyrosine (McDonald \& Chen, 1965 ) with the modifications introduced by Drucker (1972). One enzyme unit was defined as the amount of protease which releases the colour-equivalent of $1 \mu \mathrm{g}$ tyrosine in $1 \mathrm{~min}$ (Hagihara et al., 1958).

Chemicals. NAD, PMSF, casein, bovine serum albumin, ovalbumin and amino acids were obtained from Sigma. Gelatin and Casamino acids were obtained from Difco.

\section{RESULTS}

The NAD(P)ase activity of cultures of $N$. crassa wild type grown with shaking in minimal liquid medium supplemented with sucrose and transferred to other carbon sources was measured (Table 1). NAD(P)ase activity in the culture medium increased sharply when the carbon source was $0.5 \%(\mathrm{w} / \mathrm{v})$ casein. This increase was about 65 -fold when compared to conditions of complete starvation, and about 90 -fold when compared to controls (sucrose or glucose). With glycerol as carbon source the enzyme increased only 4- to 6-fold as compared to the control or starved cultures. Other carbon sources, such as cellulose, starch and Casamino acids, were inefficient in stimulating NAD(P)ase production. On the other hand, traces of sucrose or glucose were sufficient to decrease by 11 -fold the formation of NAD(P)ase when the fungus was grown on $0.5 \%(w / v)$ casein.

In view of these results, we tried other proteins as possible inducers of NAD(P)ase. We used the optimal concentrations used by other authors to induce alkaline protease from $N$. crassa (Cohen \& Drucker, 1977). Ovalbumin, gelatin, bovine serum albumin and casein were capable

\section{Table 1. Effect of carbon source on $N A D(P)$ ase production}

Conidia of $N$. crassa were inoculated into $500 \mathrm{ml}$ Vogel minimal medium containing $2 \%(\mathrm{w} / \mathrm{v})$ sucrose. After $18 \mathrm{~h}$ growth at $30^{\circ} \mathrm{C}$ with shaking, the mycelia were harvested by filtration, divided and suspended in $25 \mathrm{ml}$ Vogel salts with the indicated carbon source and incubated for $6 \mathrm{~h}$ as before. NAD(P)ase was assayed in culture filtrates. Specific activity is expressed as units per $\mathrm{mg}$ dry wt. The results are the means of three different cultures.

\section{Carbon source}

None

$2 \%$ Sucrose

$2 \%$ Glucose

$1 \%$ Cellulose

$1 \%$ Starch

$1 \%$ Glycerol

$0.5 \%$ Casein

$0.5 \%$ Casein plus $0.1 \%$ glucose

$0.5 \%$ Casein plus $0.1 \%$ sucrose

$0.5 \%$ Casamino acids
NAD(P)ase specific activity

0.011

0.008

0.007

ND

0.008

0.045

0.721

0.062

0.063

0.007

ND, Not detected (less than 0.006 units). 
Table 2. Effect of different protein substrates on $N A D(P)$ ase production

Culture conditions were as indicated in the legend to Table 1, except that the mycelia were resuspended in Vogel salts plus the indicated protein. $\mathrm{NAD}(\mathrm{P})$ ase was assayed in culture filtrates. The results are expressed as means $\pm S D$ for at least three replicates.

\begin{tabular}{lc}
\multicolumn{1}{c}{ Protein } & $\begin{array}{c}\text { NAD(P)ase } \\
\text { specific activity }\end{array}$ \\
$1 \%$ Ovalbumin & $0.14 \pm 0.02$ \\
$0.25 \%$ Gelatin & $0.55 \pm 0.07$ \\
$1 \%$ Bovine serum albumin & $0.89 \pm 0.13$ \\
$0.5 \%$ Casein & $1.09 \pm 0.25$
\end{tabular}

Table 3. Effect of nitrogen, carbon and sulphur starvation on $N A D(P)$ ase production

Conidia of $N$. crassa were inoculated into Vogel minimal medium containing $2 \%(w / v)$ sucrose. After $18 \mathrm{~h}$ growth, the mycelia were collected by filtration, suspended in fresh Vogel salts with omission of the indicated nutrient salt and the addition of $1 \%(\mathrm{w} / \mathrm{v})$ casein, and incubated for $6 \mathrm{~h}$ with shaking. $\mathrm{NAD}(\mathrm{P})$ ase was assayed in culture filtrates. The results are expressed as means $\pm \mathrm{SD}$ for at least three replicates.

$\begin{array}{lc}\text { Starvation condition } & \begin{array}{c}\text { NAD(P)ase } \\ \text { specific activity }\end{array} \\ \text { Carbon } & 0.73 \pm 0.16 \\ \text { Nitrogen } & 0.02 \pm 0.01 \\ \text { Sulphur } & 0.01 \pm 0.005 \\ \text { Carbon and nitrogen } & 0.62 \pm 0.23 \\ \text { Carbon and sulphur } & 0.83 \pm 0.18 \\ \text { Nitrogen and sulphur } & 0.01 \pm 0.003\end{array}$

of stimulating synthesis of the enzyme (Table 2). NAD(P)ase activity was practically the same in casein or bovine serum albumin, and these proteins were better inducers of NAD(P)ase than gelatin and ovalbumin. The latter protein was a very poor inducer.

The induction of $\mathrm{NAD}(\mathrm{P})$ ase by carbon starvation in the presence of protein as an alternative source is known to promote induction of protease in $N$. crassa (Drucker, 1972). Keeping this in mind, we assayed NAD(P)ase activity under other conditions that also increased the level of proteases, such as starvation for nitrogen or sulphur, or for combinations of nitrogen, sulphur and carbon (Cohen et al., 1975; Cohen \& Drucker, 1977). The only condition that promoted NAD(P)ase synthesis was carbon starvation (Table 3). Starvation for both carbon and nitrogen or both carbon and sulphur had no effect on NAD(P)ase level. Because of the marked change in the concentration of NAD(P)ase when $N$. crassa was grown on proteins as carbon source, we assayed the enzyme when the mycelia were incubated with PMSF, a inhibitor of alkaline protease activity (Cohen \& Drucker, 1977). We incubated the mycelia for $6 \mathrm{~h}$ in Vogel salts plus $0.5 \%(\mathrm{w} / \mathrm{v})$ casein and $1 \mathrm{mM}-\mathrm{PMSF}$. When used in vivo the inhibitor reduced the mycelial NAD(P)ase level 40-fold and that of the soluble enzyme 35-fold in comparison with the control. This concentration of PMSF did not inhibit NAD(P)ase activity when assayed in vitro (data not shown).

The results with PMSF suggested that the production of NAD(P)ase might be somehow linked to that of proteases. This hypothesis was tested again by supplementing the carbondeficient medium with various amino acids. Some of them are known to drastically repress protease biosynthesis (Cohen \& Drucker 1977). The effects of some amino acids or a mixture of them (Casamino acids) on the production of NAD(P)ase and alkaline protease are given in Table 4. Methionine, cysteine, phenylalanine or tryptophan markedly repressed (by more than $75 \%$ ) production of $\mathrm{NAD}(\mathrm{P})$ ase and alkaline protease; alanine and glycine repressed NAD(P)ase production by only about $25 \%$. Glutamic acid and lysine had no effect on NAD(P)ase production. The effects of amino acids on alkaline protease levels were similar to those on NAD(P)ase, except for lysine, which repressed protease but not NAD(P)ase. Casamino acids strongly repressed the biosynthesis of both NAD(P)ase and alkaline protease. 


\section{Table 4. Effects of amino acids on $N A D(P)$ ase production}

Conidia of $N$. crassa were inoculated into Vogel minimal medium containing $2 \%(w / v)$ sucrose. After $18 \mathrm{~h}$ growth, the mycelia were harvested by filtration and suspended for $8 \mathrm{~h}$ in fresh Vogel salts with $0.5 \%$ casein plus the indicated amino acid $(10 \mathrm{~mm})$ or Casamino acids $(0.1 \%)$. Enzymes were assayed in culture filtrates after dialysis against distilled water. The specific activity corresponding to $100 \%$ was $1.51 \pm 0.21$ units (mg dry wt) ${ }^{-1}$ for alkaline phosphatase and $0.74 \pm 0.12$ units (mg dry wt) ${ }^{-1}$ for $\mathrm{NAD}(\mathrm{P})$ ase. Three replicate experiments were done.

$\begin{array}{lcc} & \begin{array}{c}\text { NAD(P)ase } \\ \text { specific activity }\end{array} & \begin{array}{c}\text { Alkaline protease } \\ \text { specific activity }\end{array} \\ \text { Amino acid(s) } & (\%) & (\%) \\ \text { None (control) } & 100 & 100 \\ \text { Alanine } & 76 & 83 \\ \text { Glycine } & 79 & 75 \\ \text { Aspartic } & 76 & 75 \\ \text { Glutamic } & 106 & 88 \\ \text { Lysine } & 118 & 39 \\ \text { Methionine } & 24 & 17 \\ \text { Cysteine } & 7 & 10 \\ \text { Phenylalanine } & 9 & 0 \\ \text { Tryptophan } & 4 & 0 \\ \text { Casamino acids } & 26 & 9\end{array}$

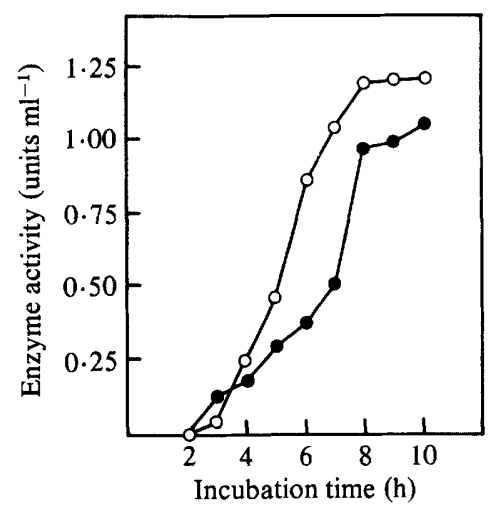

Fig. 1. NAD(P)ase and alkaline protease production by $N$. crassa in the NAD(P)ase-inducing medium containing $1 \%(\mathrm{w} / \mathrm{v})$ casein. Conidia were inoculated into $50 \mathrm{ml}$ Vogel minimal medium containing $2 \%$ (w/v) sucrose. After $18 \mathrm{~h}$ growth, the mycelia were harvested by filtration, washed with sterile water and suspended in $100 \mathrm{ml}$ fresh Vogel salts with $0.5 \%(\mathrm{w} / \mathrm{v})$ casein as sole carbon source. The culture was reincubated with shaking at $30^{\circ} \mathrm{C}$. At $1 \mathrm{~h}$ intervals, $3 \mathrm{ml}$ samples of culture were removed and the mycelium was separated from the culture medium by filtration. Culture filtrate was assayed for NAD(P)ase $(O)$ and alkaline protease $(O)$.

Our results with alkaline protease were quite similar to those obtained by Cohen $\&$ Drucker (1977). However, in our experiments, protease was induced without adding a low concentration of sugar to the induction medium. This was omitted because, as previously shown, $0.1 \%$ of glucose or sucrose was sufficient to cause NAD(P)ase repression. The mycelial mats which were used for the induction experiments had not been previously starved to deplete the endogenous sugar pool, as described by Drucker (1975); thus it is likely that these cells contained sufficient endogenous energy reserves to permit the initiation of protease synthesis.

To determine if NAD(P)ase appeared in the culture medium in synchrony with alkaline protease, mycelia grown in Vogel salts plus $2 \%(\mathrm{w} / \mathrm{v})$ sucrose were harvested by filtration and suspended in fresh Vogel salts with $1 \%(\mathrm{w} / \mathrm{v})$ casein as carbon source. At $1 \mathrm{~h}$ intervals samples were removed and assayed for extracellular NAD(P)ase and alkaline protease. The two enzymes began to appear in the medium in detectable amounts after $3 \mathrm{~h}$ incubation (Fig. 1). After this 
time, the increase of NAD(P)ase paralleled that of alkaline protease, and it ceased after about $8 \mathrm{~h}$ of incubation.

\section{DISCUSSION}

This work shows, for the first time, that NAD(P)ase synthesis in Neurospora crassa is somehow related to carbon nutrition. NAD(P)ase production was induced by the presence of protein as the sole carbon source in the culture medium, and more efficient carbon sources such as sucrose and glucose were repressors of $\mathrm{NAD}(\mathrm{P})$ ase production (Table 1). It is interesting that NAD(P)ase was induced, in the presence of protein, even in shaken cultures, in which NAD(P)ase synthesis has previously been shown to be inhibited (Stine, 1968; Nelson et al., 1976).

Microscopic examination of the induced shaken cultures revealed the absence of conidia or chains of proconidia (data not shown), which in surface cultures are normally responsible for NAD(P)ase production in N. crassa (Stine, 1968; Combépine \& Turian, 1970; Urey, 1971; Nelson et al., 1976).

Our results also suggested that $\mathrm{NAD}(\mathrm{P})$ ase synthesis was related to alkaline protease synthesis. Production of alkaline protease requires the presence of an extracellular protein as an alternative nutritional source during deprivation of carbon, nitrogen or sulphur (Drucker, 1972; Cohen \& Drucker, 1977; Cohen et al., 1975; Hanson \& Marzluf, 1973, 1975; Metzenberg, 1979). The proteases secreted under the three different conditions were indistinguishable biochemically and immunologically (Cohen et al., 1975; Hanson \& Marzluf, 1975). Hanson \& Marzluf (1975) isolated from nature a strain that had a protease with altered electrophoretic mobility and showed that the alteration was present in the proteases produced under nitrogen, sulphur or carbon starvation. These authors concluded that the structural gene for alkaline protease was under control of three different regulatory circuits.

The biological role of $\mathrm{NAD}(\mathrm{P})$ ase in $N$. crassa is still unknown. In our experiments $\mathrm{NAD}(\mathrm{P})$ ase and alkaline protease were simultaneously induced in the presence of protein (Fig. 1). The production of the two enzymes was inhibited by PMSF, and no activity could be detected either in the culture medium or in the crude mycelial extracts. The biochemical mechanism of the PMSF effect is not clear, but it was not a consequence of a general inhibition of protein synthesis or secretion because another extracellular enzyme, aryl- $\beta$-glucosidase, was both synthesized and secreted in a normal manner by conidia germinating in the presence of cellobiose as inducer, and $1 \mathrm{mM}-\mathrm{PMSF}$ (unpublished results). In any case, the parallel production of NAD(P)ase and protease appeared to indicate, at first glance, that NAD(P)ase production was dependent on that of protease. If this were correct, NAD(P)ase would be produced in any condition that promoted alkaline protease formation. However, starvation for either nitrogen or sulphur did not stimulate NAD(P)ase production (Table 3). Other results arguing against this hypothesis were obtained with nada (NAD(P)ase-deficient) and $c r-1$ (crisp) mutants. In the former, proteolytic activity was comparable to that of the wild type strain (data not shown), and in the latter, the NAD(P)ase level was high (Jorge \& Terenzi, 1980) but only traces of alkaline protease were secreted (E. S. Savtchencko and co-workers, unpublished).

The other possibility was that NAD(P)ase and alkaline protease synthesis were related at the control level. This was supported by the simultaneous occurrence of the enzymes in proteinsupplemented medium (Fig. 1), and also by the fact that NAD(P)ase and protease were repressed in parallel by the same amino acids (Table 4). Thus, under conditions of carbon starvation NAD(P)ase and alkaline protease might be co-regulated by a common control gene. The existence of a control gene coordinating the expression of a family of enzymes which allows the organism to utilize alternative carbon sources was suggested by Hanson \& Marzluf (1975), but has not been genetically demonstrated. It might be worthwhile to search for mutants deficient in the formation of NAD(P)ase and alkaline protease under carbon-limited conditions, as a way of investigating the mechanism controlling these two enzymes.

This work was supported by a grant from the Conselho Nacional de Desenvolvimento Cientifico e Tecnológico (CNPq - PIG. Proc. 402534/82). 


\section{REFERENCES}

Cohen, B. L. \& Drucker, H. (1977). Regulation of exocellular protease in Neurospora crassa: induction and repression under conditions of nitrogen starvation. Archives of Biochemistry and Biophysics 182, 601-613.

Cohen, B. L., Morris, J. E. \& DruCKer, H. (1975). Regulation of two extracellular proteases of Neurospora crassa by induction and by carbon-nitrogen and sulfur-metabolite repression. Archives of Biochemistry and Biophysics 169, 324-330.

CombépINE, G. \& TURIAN, G. (1970). Activités de quelques enzymes associés à la conidiogenèse du Neurospora crassa. Archiv für Mikrobiologie 72, 3647.

DRUCKER, H. (1972). Regulation of exocellular proteases in Neurospora crassa: induction and repression of enzyme synthesis. Journal of Bacteriology 110, 1041-1049.

DRUCKER, H. (1975). Regulation of exocellular proteases in Neurospora crassa: metabolic requirements of the process. Journal of Bacteriology 122, 11171125.

Hagihara, B., Matsubara, H., Nakay, M. \& OKunUKI, K. (1958). Crystalline bacterial proteinase. I. Preparation of crystalline proteinase of Bacillus subtilis. Journal of Biochemistry 45, 185-194.

Hanson, M. A. \& Marzluf, G. A. (1973). Regulation of a sulfur-controlled protease in Neurospora crassa. Journal of Bacteriology 116, 785-789.

Hanson, M. A. \& Marzluf, G. A. (1975). Control of the synthesis of a single enzyme by multiple regulatory circuits in Neurospora crassa. Proceedings of the National Academy of Sciences of the United States of America 72, 1240-1244.

HOCHBERG, M. L. \& SARGENT, M. L. (1974). Rhythms of enzyme activity associated with circadian conidiation in Neurospora crassa. Journal of Bacteriology 120, 1164-1175.

Jorge, J. A. \& TerenzI, H. F. (1980). An enzymatic alteration secondary to adenylyl cyclase deficiency in the $\mathrm{cr}-I$ (crisp) mutant of Neurospora crassa. Developmental Biology 74, 164-177.

Kaplan, N. O., Colowick, S. P. \& Nason, A. (1951). Neurospora diphosphopyridine nucleotidase. Journal of Biological Chemistry 191, 473-483.

McDonald, C. E. \& Chen, L. L. (1965). The Lowry modification of the Folin reagent for determination of proteinase activity. Analytical Biochemistry 10, 175-177.

MetZenberG, R. L. (1979). Implications of some genetic control mechanisms in Neurospora. Microbiological Reviews 43, 361-383.

Nason, A., Kaplan, N. O. \& Colowick, S. P. (1951). Changes in enzymatic constitution in zinc-deficient Neurospora. Journal of Biological Chemistry 188, 397406.

Nelson, R. E., Selitrennikoff, C. P. \& Siegel, R. W. (1975). Mutants of Neurospora deficient in nicotinamide adenine dinucleotide (phosphate) glycohydrolase. Journal of Bacteriology 122, 695-709.

Nelson, R. E., Selitrennikoff, C. P. \& Siegel, R. W. (1976). Developmental regulation of nicotinamide adenine dinucleotide (phosphate) glycohydrolase in Neurospora crassa. Developmental Biology 50, 122133.

Stine, G. J. (1968). Enzyme activities during the asexual cycle of Neurospora crassa. II. NAD and NAD-dependent glutamic dehydrogenase and nicotinamide adenine dinucleotidase. Journal of Cell Biology 37, 81-88.

UREY, J. C. (1971). Enzyme patterns and protein synthesis during synchronous conidiation in Neurospora crassa. Developmental Biology 26, 17-27.

VOGEL, H. J. (1956). A convenient growth medium for Neurospora (medium N). Microbial Genetics Bulletin 13, 42-43.

Zalokar, M. \& Cochrane, V. W. (1956). Diphosphopyridine nucleotidase in the life cycle of Neurospora crassa. American Journal of Botany 43, 107-110. 